\title{
MATERIALS TECHNOLOGY FOR GaSb-BASED OPTOELECTRONIC DEVICES*
}

A. Piotrowska, E. Kamińska, T.T. Piotrowski, M. Piskorski, M. Guziewicz, E. Papis, K. Golaszewska-Malec and S. Kasjuniuk

Institute of Electron Technology, Al. Lotników 32/46, 02-668 Warszawa, Poland

A study is made of surface preparation, metallization, patterning and dielectric deposition with the aim of developing process technology for GaSb-based photonic devices.

PACS numbers: $73.40 . \mathrm{Ns}, 81.05 . \mathrm{Ea}, 81.40 .-\mathrm{z}$

\section{Introduction}

Semiconducting antimonide compounds have received increasing attention as the alternative materials for midinfrared photonic devices, with a variety of applications such as remote sensing, pollution monitoring, and molecular spectroscopy [1]. In this paper we present the results of our recent work towards the development of a fabrication technology for GaSb-based devices. Specifically, we have conducted a study of etchants, metal contacts, and dielectrics for application to light emitting diodes (LEDs) and double-channel mesa-structure laser diodes (LDs).

Our work was conducted on commercially available (100) oriented $\mathrm{GaSb}$ monocrystalline substrates, both $p$-type and $n$-type, with doping level of $1 \div 5 \times 10^{18} \mathrm{~cm}^{-3}$ and $1 \times 10^{17} \mathrm{~cm}^{-3}$ respectively, and $\mathrm{GaSb} / \mathrm{Al}_{x} \mathrm{Ga}_{1-x} \mathrm{As}_{y} \mathrm{Sb}_{1-y}$ $(x=0.20 \div 0.5, y=0.03)$ structures grown by liquid phase epitaxy. Substrates were initially chemo-mechanically polished with bromine in ethylene glycol $(1: 8)$ solution.

\section{Etching studies}

We have investigated etching processes as a means for well-controlled treatment of the surface before deposition of metallic and dielectric layers, as well as for patterning of mesa structures. The effects of various etches on GaSb-based materials were studied with special attention paid to surface quality, etching rate and etching profile. Etches studied included aqueous solutions of $\mathrm{HF}, \mathrm{HCl}$ and $\mathrm{NH}_{4} \mathrm{OH}$, which were proved to be effective in removal of native oxides from GaAs, various combinations of $\mathrm{Br}_{2}-\mathrm{HNO}_{3}-\mathrm{HCl}-\mathrm{CH}_{3} \mathrm{COOH}$, and $\mathrm{HCl}-\mathrm{H}_{2} \mathrm{O}_{2}-\mathrm{H}_{2} \mathrm{O}$. From among the solutions we examined, $\mathrm{HF}, \mathrm{HCl}$ and $\mathrm{NH}_{4} \mathrm{OH}$-based solutions had very low etching rates (about $10 \mathrm{~nm} / \mathrm{min}$ ) and the surface remained smooth and featureless.

*The present work has received a financial support from the European Community Copernicus Project no. CIPA-CT94-0158. 
$\mathrm{HCl}-\mathrm{H}_{2} \mathrm{O}_{2}-\mathrm{H}_{2} \mathrm{O}(60+1+1)$ gave good results for the surface quality, and a reasonable etch rate of $4.4 \mu \mathrm{m} / \mathrm{min}$ for $\mathrm{GaSb}$ and $3 \mu \mathrm{m} / \mathrm{min}$ for $\mathrm{Al}_{x} \mathrm{Ga}_{1-x} \mathrm{As}_{y} \mathrm{Sb}_{1-y}$.

Taking into account the LD structure, we were interested in etching through $p$-GaSb $(0.5 \mu \mathrm{m}) / p$-GaAlAsSb $(2.5 \mu \mathrm{m})$ epitaxial layers to form a double-channel mesa structure in $n$-GaSb substr $/ n$-GaAlAsSb $/ n$-GaInAsSb $/ p$-GaAlAsSb $/ p$-GaSb heterostructure. Etching studies included both wet and dry reactive ion etching (RIE) processes. Etching tests were conducted by forming an appropriate etch mask on the surface of the sample. The mask was examined prior to removal for any degradation, and an etch depth was measured afterwards by means of an alpha-step stylus profilometer and scanning electron microscope. Of all the etches studied, $\mathrm{HCl}-\mathrm{H}_{2} \mathrm{O}_{2}-\mathrm{H}_{2} \mathrm{O}(60+1+1)$ solution was found the most suitable for patterning purposes. This solution does not erode the photoresist. Figure 1a shows a feature etched into $\mathrm{GaSb} / \mathrm{Al}_{x} \mathrm{Ga}_{1-x} \mathrm{As}_{y} \mathrm{Sb}_{1-y}$ structure using wet etching. Let us note that the overetching is $3 \mu \mathrm{m} /$ side.

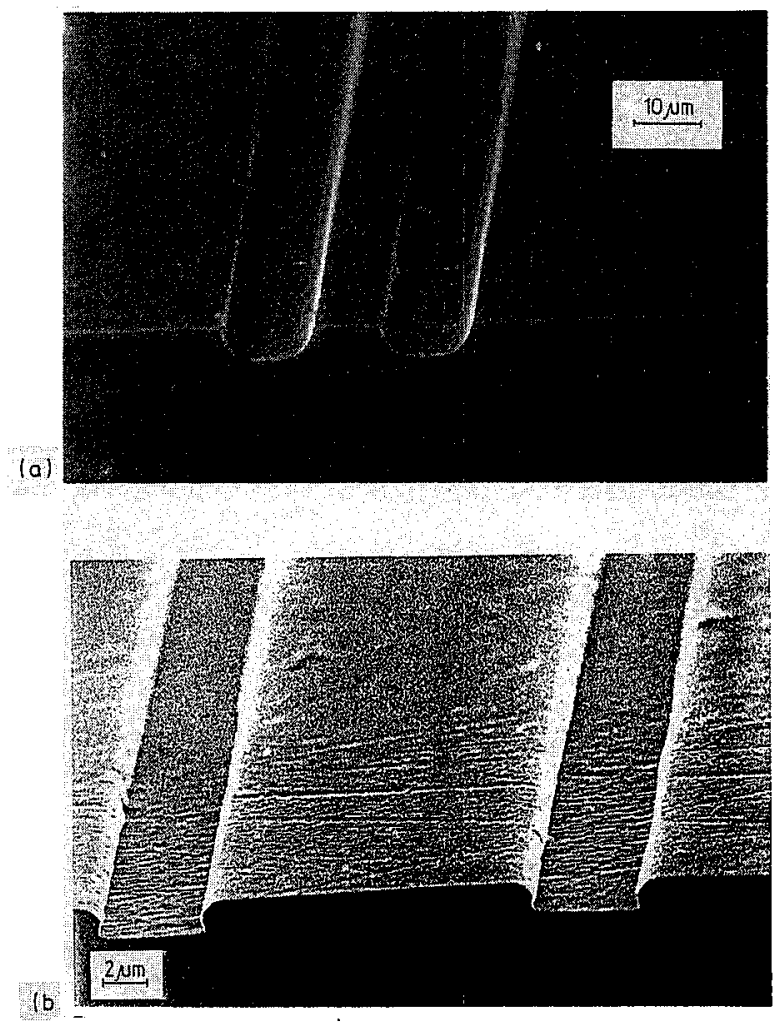

Fig. 1. Double channel mesa structure in $\mathrm{Al}_{x} \mathrm{Ga}_{1-x} \mathrm{As}_{y} \mathrm{Sb}_{1-y} / \mathrm{GaSb}$ (the etch mask consisted of $16 \mu \mathrm{m}$ wide mesas and $4 \mu \mathrm{m}$ wide channels): (a) wet etching in $\mathrm{HCl}+\mathrm{H}_{2} \mathrm{O}_{2}+\mathrm{H}_{2} \mathrm{O}$. Channel depth $5 \mu \mathrm{m}$, mesa width $10 \mu \mathrm{m}$; (b) reactive ion etching in $\mathrm{CCl}_{4} / \mathrm{H}_{2}$. Channel depth $2 \mu \mathrm{m}$, mesa width $16 \mu \mathrm{m}$. 
Reactive ion etchings were performed in a diode configuration RIE chamber with a $13.56 \mathrm{MHz}$ power supply, using $\mathrm{CCl}_{2} \mathrm{~F}_{2} / \mathrm{H}_{2}$ and $\mathrm{CCl}_{4} / \mathrm{H}_{2}$ process gases. The optimum etch conditions providing vertical side walls and residue free etch surfaces, at considerable etch rates were obtained with $\mathrm{CCl}_{4} / \mathrm{H}_{2}$ plasma at a pressure of $150 \mu \mathrm{bar}, \mathrm{rf}$ applied power of $30 \mathrm{~W}$, and gas flow rate $7 / 12$. The etch rate was $200 \mathrm{~nm} / \mathrm{min}$. Since the etching agent damages the photoresist mask, RIE experiments were carried out using a $\mathrm{SiO}_{2} / \mathrm{Cr}$ double layer mask. In Fig. $1 \mathrm{~b}$ an example of a double channel mesa structure formed by RIE in $\mathrm{GaSb} / \mathrm{Al}_{x} \mathrm{Ga}_{1-x} \mathrm{As}_{y} \mathrm{Sb}_{1-y}$ is presented. Note, resulting vertical side walls profiles.

\section{Metal contacts}

We have examined Ag-based, Au-based and refractory metal-based metallizations. Metal contacts were patterned by lift-off lithography. After metallization contacts were annealed at $100 \div 400^{\circ} \mathrm{C}$ for 3 min in hydrogen.

Ag-based metallization was deposited by sputtering in $\mathrm{Ar}$ atmosphere. We have used $\mathrm{Ag}-\mathrm{Mn}(4 \%), \mathrm{Ag}-\mathrm{Cd}(2 \%), \mathrm{Ag}-\mathrm{Si}(4 \%)$ targets for contacts to $p$-type substrates, and $\mathrm{Ag}-\mathrm{Te}(1.5 \%)$ and $\mathrm{Ag}-\mathrm{Se}(1.5 \%)$ for $n$-type GaSb.

$\mathrm{Au}$-based metallization was deposited by thermal evaporation of source materials in a vacuum of $2 \times 10^{-6}$ torr. Contact layers, which we examined, included $\mathrm{Au}, \mathrm{AuZn}$ and $\mathrm{AuSb}$ for $p$-type, and AuGeNi and AuSb for $n$-type.

Pure $\mathrm{Pt}$ and $\mathrm{Pt}$ with the $\mathrm{Cr}$-adhesion layer were deposited by DC magnetron sputtering in Ar atmosphere. TiN metallization with the Ti-adhesion film was deposited by $\mathrm{RF}$ reactive magnetron sputtering from the Ti target in $\mathrm{Ar} / \mathrm{N}_{2}(30 \%)$ atmosphere.

For $p$-type material all contacts studied gave linear $I-V$ characteristics but $\mathrm{Au}$-based contacts had the lowest resistances of approximately $1 \times 10^{-5} \Omega \mathrm{cm}^{2}$. For $n$-type materials, contact resistances were uniformly higher with the resistance of ca. $5 \times 10^{-4} \Omega \mathrm{cm}^{2}$. They gave good adhesion for lift-off lithography and bonding.

\section{Dielectrics}

Five types of dielectric films were investigated: $\mathrm{SiO}_{2}, \mathrm{Si}_{3} \mathrm{~N}_{4}, \mathrm{SiO}_{2} / \mathrm{Si}_{3} \mathrm{~N}_{4}$ sandwich structure, $\mathrm{Al}_{2} \mathrm{O}_{3}$ and $\mathrm{TiO}_{2}$, deposited by $\mathrm{RF}$ magnetron sputtering in $\mathrm{Ar}$. After deposition of dielectric films, $200 \mathrm{~nm}$ thick Au metallization, was deposited and patterned for electrical measurements (circular dots with diameter of 180 ,

TABLE

Electrical properties of dielectric films.

\begin{tabular}{l|c|c|c}
\hline \hline \multicolumn{1}{c|}{ Dielectric } & Current at 10 V & Local breakdown voltage & Breakdown voltage \\
\hline $\mathrm{SiO}_{2}$ & $10-100 \mathrm{pA}$ & $30-35 \mathrm{~V}$ & $100 \mathrm{~V}$ \\
$\mathrm{Si}_{3} \mathrm{~N}_{4}$ & $20-100 \mu \mathrm{A}$ & - & - \\
$\mathrm{SiO}_{2} / \mathrm{Si}_{3} \mathrm{~N}_{4}$ & $30-100 \mathrm{pA}$ & $30-40 \mathrm{~V}$ & $70 \mathrm{~V}$ \\
$\mathrm{Al}_{2} \mathrm{O}_{3}$ & $1-500 \mathrm{pA}$ & $20 \mathrm{~V}$ & $80-90 \mathrm{~V}$ \\
$\mathrm{TiO}_{2}$ & $>1 \mathrm{~mA}$ & - & -
\end{tabular}


$250,350,500,700$, and $1000 \mu \mathrm{m})$. The electrical characterization involved $I-V$ measurements for voltages up to $100 \mathrm{~V}$, for forward and reverse bias conditions. The results of breakdown voltage measurements are given in Table.

At the present stage of investigations we can state that $\mathrm{SiO}_{2}$ dielectric films exhibit the best electrical performance.

The results of these investigations have been applied to fabricate LEDs and LDs operating at $\lambda=2.0 \div 2.3 \mu \mathrm{m}$ at RT.

\section{Acknowledgments}

We would like kindly acknowledge Drs. M. Sawicki and J. Wróbel from the Institute of Physics, PAS, for making SEM pictures shown in this article:

\section{References}

[1] H. Lee, P.K. York, R.J. Menna, R.U. Martinelli, D.Z. Garbuzov, S.Y. Narayan, J.C. Connolly, Appl. Phys. Lett. 66, 1942 (1995). 